\title{
Article \\ Ethical Considerations in Clinical Trials for Disorders of Consciousness
}

\author{
Michael J. Young ${ }^{1, *(\mathbb{D})}$, Yelena G. Bodien ${ }^{1,2}$ and Brian L. Edlow 1,3 (D) \\ 1 Center for Neurotechnology and Neurorecovery, Department of Neurology, Harvard Medical School, \\ Massachusetts General Hospital, Boston, MA 02114, USA; ybodien@mgh.harvard.edu (Y.G.B.); \\ bedlow@mgh.harvard.edu (B.L.E.) \\ 2 Department of Physical Medicine and Rehabilitation, Harvard Medical School, Spaulding Rehabilitation \\ Hospital, Charlestown, MA 02114, USA \\ 3 Athinoula A. Martinos Center for Biomedical Imaging, Harvard Medical School, Massachusetts General \\ Hospital, Charlestown, MA 02114, USA \\ * Correspondence: Michael.Young@mgh.harvard.edu; Tel.: +1-61-7726-2000
}

Citation: Young, M.J.; Bodien, Y.G.; Edlow, B.L. Ethical Considerations in Clinical Trials for Disorders of Consciousness. Brain Sci. 2022, 12, 211. https://doi.org/10.3390/ brainsci12020211

Academic Editor: Sergio Bagnato

Received: 11 January 2022

Accepted: 28 January 2022

Published: 2 February 2022

Publisher's Note: MDPI stays neutral with regard to jurisdictional claims in published maps and institutional affiliations.

Copyright: (C) 2022 by the authors. Licensee MDPI, Basel, Switzerland. This article is an open access article distributed under the terms and conditions of the Creative Commons Attribution (CC BY) license (https:// creativecommons.org/licenses/by/ $4.0 /)$.

\begin{abstract}
As the clinical trial landscape for patients with disorders of consciousness (DoC) expands, consideration of associated ethical challenges and opportunities is of ever-increasing importance. Responsible conduct of research in the vulnerable population of persons with DoC, including those with coma, vegetative state/unresponsive wakefulness syndrome (VS/UWS), minimally conscious state (MCS), covert cortical processing (CCP), and cognitive motor dissociation (CMD), demands proactive deliberation of unique ethical issues that may arise and the adoption of robust protections to safeguard patients, surrogates, and other key stakeholders. Here we identify and critically evaluate four central categories of ethical considerations in clinical trials involving participants with DoC: (1) autonomy, respect for persons and informed consent of individuals with liminal consciousness; (2) balancing unknown benefits and risks, especially considering the epistemological gap between behavior and consciousness that complicates ordinary ascription of subjective states; (3) disclosure to surrogates and clinical teams of investigational results pertaining to consciousness; and (4) justice considerations, including equitable access to clinical trial enrollment across communities and geographies. We outline guiding principles and research opportunities for clinicians, neuroethicists, and researchers engaged in DoC clinical trials to advance ethical study design and deployment in this complex yet crucial area of investigation.
\end{abstract}

Keywords: coma; consciousness; neuroethics; philosophy; minimally conscious state; clinical trials

\section{Introduction}

Mounting mechanistic understanding of human consciousness and its manifold disorders has paved the way for the emergence of numerous promising strategies to detect, predict and promote recovery of consciousness following severe brain injury. As the clinical trial landscape for patients with disorders of consciousness (DoC) expands, consideration of associated ethical challenges and opportunities is of ever-increasing importance. Responsible conduct of research and, especially, clinical trials in the vulnerable population of people with $\mathrm{DoC}$, including persons with coma, vegetative state/unresponsive wakefulness syndrome (VS/UWS), minimally conscious state (MCS), covert cortical processing (CCP), and cognitive motor dissociation (CMD), demand proactive consideration of unique ethical issues that may arise and the adoption of robust protections to safeguard participants, surrogates, and other key stakeholders, while fostering a productive and trustworthy research enterprise.

Here we identify and critically evaluate four central categories of ethical considerations in clinical trials involving participants with DoC: (1) autonomy, respect for persons, and consent of individuals with liminal consciousness and lack of decision-making capacity; 
(2) balancing unknown benefits and risks, especially considering the epistemological gap between behavior and consciousness that complicates ordinary ascription of subjective states; (3) disclosure of investigational results pertaining to consciousness to surrogates and clinical teams, and data management; and (4) justice considerations, including equitable access to clinical trial enrollment across communities and geographies. While these dimensions by no means exhaust the whole ambit of neuroethics in DoC research, they represent salient and distinctive issues identified in our collective experience designing and conducting clinical trials involving patients with DoC, corresponding ethical and philosophical themes discerned through a review of the literature, and normative analysis. We outline guiding principles for clinicians and researchers engaged in DoC clinical trials to advance ethical study design and deployment in this complex yet crucial research area. While the present analysis focuses on ethical considerations in clinical trials for persons with DoC, many of the issues discussed find similar expression in other forms of research involving persons with DoC.

What differentiates clinical trials from other research studies? Clinical trials are defined by the National Institutes of Health (NIH) as a particular kind of research study in which "human subjects are prospectively assigned to one or more interventions (which may include placebo or other control) to evaluate the effects of those interventions on healthrelated biomedical or behavioral outcomes" [1]. An intervention is defined by the NIH as any "manipulation of the subject or subject's environment for the purpose of modifying one or more health-related biomedical or behavioral processes and/or endpoints" [2]. The interventional nature of clinical trials heightens the need for rigorous ethical safeguards to ensure that participants are responsibly enrolled, their welfare prioritized, and protected against inappropriate risks [3-6]. This is especially the case for clinical trials involving participants with DoC whose ability to actively communicate with investigators is constitutively dampened by their brain state. As of 16 December 2021, over 200 active or pending clinical trials involving subjects with DoC were registered on ClinicalTrials.Gov; these include both observational and interventional trials involving devices, drugs, stimulation techniques, and diagnostic procedures. Each of these interventions carries a unique balance of benefits and risks, and it is beyond the present scope to extensively catalog the normative features of each investigational approach. Rather, our aim is to elucidate key shared ethical dimensions of DoC clinical trials and to evaluate their overarching implications for clinicians, investigators, patients, and surrogates.

\section{Preserving Patient Autonomy in Clinical Trials Involving Persons with DoC}

"Autonomy" etymologically derives from the Greek roots "autos" ("self") + "nomos" ("law") [7-10]. Harboring and exercising autonomy entails the faculty and practice of living one's life in accordance with one's own choices, values, and goals; the autonomous individual is thus self-governing, insofar as the laws, broadly construed, dictating the course of key decisions are self-derived and concordant with one's own vital aims. Accordingly, respecting patient autonomy in the context of clinical practice and research requires integrating patient preferences and values in decisions surrounding treatment pathways, goals of care, determination of best-interests, and participation in research studies and clinical trials. The process of voluntary and informed consent is anchored to preserving patient autonomy; in its absence, the risk of decisions being made that contravene patient preferences and thus abrogate a patient's self-rule is acutely heightened [11-14]. The doctrine of informed and voluntary consent in clinical medicine and research was ratified in the Nuremberg Code, Belmont Report and Declaration of Helsinki, and later crystalized in canonical work by bioethicists and moral philosophers, including Beauchamp and Childress' Principles of Biomedical Ethics [15-20].

Recognizing the potential for conflicting obligations that might be experienced by clinicians / investigators tasked with balancing professional duties deriving from the doctorpatient relationship with, at times, competing duties toward society and science writ large, the Declaration of Helsinki, adopted by the World Medical Association in 1964 
and updated in 2013, emphasizes that clinicians/investigators should never prioritize the pursuit of scientific knowledge over the welfare of the individual research subject. "While the primary purpose of medical research is to generate new knowledge", the Declaration stresses, "this goal can never take precedence over the rights and interests of individual research subjects. It is the duty of physicians who are involved in medical research to protect the life, health, dignity, integrity, right to self-determination, privacy, and confidentiality of personal information of research subjects" [21]. The Declaration further specifies that, when a physician discusses a research study with a patient or surrogate, he or she "must fully inform the patient which aspects of their care are related to the research. The refusal of a patient to participate in a study or the patient's decision to withdraw from the study must never adversely affect the patient-physician relationship" [21].

Regulatory codes and conventions in the United States and European Union recapitulate these ethical imperatives. In the United States, requirements for obtaining informed consent from research subjects are codified in the Code of Federal Regulations (CFR), Title 21, Chapter 1, Part 50, "Informed Consent of Human Subjects" [22]. The relevant portion of CFR specifies that "no investigator may involve a human being as a subject in research covered by these regulations unless the investigator has obtained the legally effective informed consent of the subject or the subject's legally authorized representative. An investigator shall seek such consent only under circumstances that provide the prospective subject or the representative sufficient opportunity to consider whether or not to participate and that minimize the possibility of coercion or undue influence. The information that is given to the subject or the representative shall be in language understandable to the subject or the representative. No informed consent, whether oral or written, may include any exculpatory language through which the subject or the representative is made to waive or appear to waive any of the subject's legal rights, or releases or appears to release the investigator, the sponsor, the institution, or its agents from liability for negligence" [22]. The CFR also details exceptions to the general requirements of informed consent, including situations in which the "human subject is confronted by a life-threatening situation necessitating the use of the test article, informed consent cannot be obtained from the subject because of an inability to communicate with, or obtain legally effective consent from, the subject, time is not sufficient to obtain consent from the subject's legal representative, and there is available no alternative method of approved or generally recognized therapy that provides an equal or greater likelihood of saving the life of the subject" [22]. Who qualifies as a "legally authorized representative" to provide proxy consent for research participation varies by jurisdiction [23]. While our focus here is primarily on ethical frameworks within United States and European Union, and it is beyond the present scope to canvas the complexities of consent across all regions and jurisdictions, it is important to note that approaches to informed consent in and across other regions are highly varied. Lacunae in regulatory standards of informed consent and research ethics in some regions underscore a significant need for global harmonization of approaches to informed consent to protect research participants [24-30]. Less developed regulatory oversight in some regions has contributed to a trend of "outsourcing" of global clinical trials to jurisdictions where clinical-trial conduct is perceived to be less burdensome, including areas of Eastern Europe, China, India South America, and elsewhere [26,31-36]. While some sponsors might be drawn to such practices, which some have described as a "strategic imperative" [37], it is vital to recognize that possibilities for vulnerable research participants to be exploited or unduly harmed are magnified if sufficiently robust ethical protections are lacking [36,38]. Opportunities to align global research ethics through supranational regulatory machinery and international cooperation should be recognized and strengthened. Divergent philosophical perspectives and attitudes surrounding autonomy, paternalism, and the role of the individual in society have inspired varied approaches to conceptualizing and prioritizing informed consent across cultures. For example, collectivist conceptions of personhood, family, and interdependency have been theorized to influence distinctively family-oriented paradigms of informed consent in China and Japan [39-44]. The need to advance the rigor and integrity 
of informed-consent procedures across regions represents a challenge and opportunity; building cross-cultural bridges to study and integrate divergent philosophies of autonomy with the common aim of protecting the safety and well-being of research participants, and particularly those who may lack decisional capacity, such as persons with disorders of consciousness, is a growing ethical imperative [45-49].

In 2019, a revised US Common Rule came into effect that, inter alia, requires that "[f]or each clinical trial conducted or supported by a Federal department or agency, one IRB approved informed consent form used to enroll subjects must be posted by the awardee or the Federal department or agency component conducting the trial on a publicly available Federal Web site that will be established as a repository for such informed consent forms .... no later than 60 days after the last study visit by any subject, as required by the protocol". When explaining the rationale for this new requirement, it is specified that the "primary purpose of this provision is to improve the quality of consent forms in federally funded research by assuring that-contrary to current practices, under which it is often very difficult to ever obtain a copy of these documents-they eventually would become subject to public scrutiny and that they will provide useful models for others. The consent form plays a key role in making sure that someone asked to enter a clinical trial receives the information they be making decision about whether to enroll in that trial. Accordingly, it also plays a key role in supporting and justifying the public's trust in the integrity of our clinical trial enterprise ... Fundamentally, this proposal is about increasing the transparency of one of the most important aspects of our human subjects protection system. Increased transparency is in general a good thing, and in this instance, as in many others, it offers multiple benefits-including increased trust-at very low cost". Compliance with this requirement has been variable across study sites and types [50].

In European Union (EU) member states, legal and regulatory standards around informed consent stem from the Convention on Human Rights and Biomedicine (Oveido Convention), which has been in force since 1999, and EU Regulation No. 536/2014 ("clinical trials on medicinal products for human use"), which replaces the precedent Directive 2001/20/EC [51-53]. The General Data Protection Regulation 2016/679 (GDPR) provides additional guidance and protections around data use, consent, processing, and privacy, with some variation in interpretation by state [54-58]. The Oveido Convention (Article 5-General Rule) details that "[a]n intervention in the health field may only be carried out after the person concerned has given free and informed consent to it. This person shall beforehand be given appropriate information as to the purpose and nature of the intervention as well as on its consequences and risks" [59]. Article 6 ("Protection of Persons not able to Consent") includes exceptions to the general rule for those who cannot consent, explaining that " $[\mathrm{w}]$ here, according to law, an adult does not have the capacity to consent to an intervention because of a mental disability, a disease or for similar reasons, the intervention may only be carried out with the authorisation of his or her representative or an authority or a person or body provided for by law. The individual concerned shall as far as possible take part in the authorisation procedure" [59]. Article 16 ("Protection of Persons undergoing Research") stipulates the following general requirements:

"Research on a person may only be undertaken if all the following conditions are met: (i) there is no alternative of comparable effectiveness to research on humans; (ii) the risks which may be incurred by that person are not disproportionate to the potential benefits of the research; (iii) the research project has been approved by the competent body after independent examination of its scientific merit, including assessment of the importance of the aim of the research, and multidisciplinary review of its ethical acceptability; (iv) the persons undergoing research have been informed of their rights and the safeguards prescribed by law for their protection; (v) the necessary consent as provided for under Article 5 has been given expressly, specifically and is documented. Such consent may be freely withdrawn at any time" [59].

Article 17 ("Protection of persons not able to consent to research") adds further requirements for conducting research involving persons who cannot consent, specifying 
that "[r]esearch on a person without the capacity to consent as stipulated in Article 5 may be undertaken only if all the following conditions are met: (i) the conditions laid down in Article 16, sub-paragraphs I to iv, are fulfilled; (ii) the results of the research have the potential to produce real and direct benefit to his or her health; (iii) research of comparable effectiveness cannot be carried out on individuals capable of giving consent; (iv) the necessary authorisation provided for under Article 6 has been given specifically and in writing; and (v) the person concerned does not object" [59].

For research that does not have the potential to produce direct benefits to the health of the participant who cannot consent (i.e., that fails to meet criterion ii), Article 17 adds the following exceptional condition:

"... where the research has not the potential to produce results of direct benefit to the health of the person concerned, such research may be authorised subject to the conditions laid down in ... i, iii, iv and v above, and to the following additional conditions: (i) the research has the aim of contributing, through significant improvement in the scientific understanding of the individual's condition, disease or disorder, to the ultimate attainment of results capable of conferring benefit to the person concerned or to other persons in the same age category or afflicted with the same disease or disorder or having the same condition; (ii) the research entails only minimal risk and minimal burden for the individual concerned" [59].

EU Regulation No. 536/2014 specifies additional conditions and requirements for performing research involving subjects who are not able to consent [60].

These requirements are typically operationalized by institutional internal review boards (IRBs) and may be impacted by other local rules and regulations [61]. Challenges posed by the COVID-19 pandemic motivated changes to the informed-consent process in many settings, with increased reliance on electronic consent, waivers, or remote consent methods, due to heightened infection risk posed by face-to-face informed-consent conversations [62-64].

Clinical trials involving participants with $\mathrm{DoC}$ pose a distinct challenge to the doctrine of informed consent insofar as participants by definition are unable to actively engage in decision-making [65]. However, discovery of novel therapies for this population is crucial, with survivors facing severely limited treatment options and high rates of mortality, morbidity, and long-term neurological disability [66-70]. Recognizing this challenge, Fins and colleagues incisively state that "[p]aradoxically ... those with disorders of consciousness often have been protected from the research enterprise by regulatory exclusion, which inverts the justice ethos of Belmont" [71]. Instead, they argue that there is a "need for inclusion of decisionally incapacitated subjects in research as long as it is ethically proportionate and attentive to foreseeable risks and benefits ... The ethical challenge for investigators is to study this population to learn more about their cognitive capabilities and to include these subjects, as they are able, in the consent or assent process, recognizing that subjects may reveal a greater capability to engage with the investigative team" [71] as a result of the research being conducted or in the natural history of recovery. Thus, rather than categorically disenfranchising incapacitated persons with DoC from clinical trials due to inability to provide direct consent, alternative models to responsibly study persons with DoC have been adopted by investigators. These models include surrogate (proxy) consent, consensus consent, deferred consent, community consultation, and waiver of consent [72-78]. Each of these models endeavors to uphold participant autonomy and protect patient welfare, despite the inability to obtain direct, synchronous informed consent from the person with DoC.

In other contexts involving acutely injured or critically ill patients, researchers and clinicians have worked closely with ethicists to design study paradigms balancing principles of respect for patient autonomy, beneficence, justice, and non-maleficence, whilst facilitating research inclusion. Alternative paradigms of consent that may ensure protection of subjects' autonomy without restricting responsible participation in research include the following: (i) surrogate consent (by legally appointed or default proxy decision-maker), 
(ii) waiver of informed consent utilizing a federal exception from informed consent (EFIC), (iii) deferral of consent with retrospective debriefing, (iv) a consent substitute model, and (v) community consultation [79-85]. Elements of each of these paradigms might be variably integrated into a hierarchical, adaptive, or multimodal system of informed consent to be deployed in a DoC clinical trial where variation in participant capacity or surrogate availability is anticipated.

Independently, each of these models carries a distinctive array of ethical and operational benefits and challenges. For example, while surrogate consent is perhaps the most ubiquitous approach when conducting research involving incapacitated persons, the ability of a surrogate to provide consent may be precluded by restricted time windows to enrollment, or may be compromised by psychological stress induced by a high-acuity brain injury in a loved one. Moreover, surrogate decision-makers are often unknown or unavailable in acute settings, and where they are available, they may not be familiar with the participant's wishes [86-93].

In 1996, recognizing the growing need to include patients with emergent pathologies in research despite a lack of capacity commonly occasioned by high-acuity and timesensitivity, the United States Food and Drug Administration (FDA) and Department of Health and Human Services (HHS) developed regulations that allowed for studies to proceed in acute situations where current treatment paradigms are considered unsatisfactory. These are known as EFIC regulations and waiver of informed consent (WIC) regulations [94]. Whereas EFIC regulations apply to research involving drugs or devices, WIC regulations apply to research involving non-FDA regulated modalities, such as comparisons of standards of care. Over the past 25 years, the FDA has granted over 40 EFICs for trials that have collectively enrolled over 40,000 patients, including trials of interventions and devices for cardiac arrest, septic shock, traumatic brain injury, status epilepticus, stroke, respiratory failure, and acute coronary syndrome [82,95]. However, the processes required to satisfy these requirements are rigorous and demand meticulous attention to ensure ethical appropriateness and regulatory adherence [94,96]. Deferral of consent procedures, whereby patients are asked to provide informed consent only after enrollment or potentially recovery, have occasionally been used in emergency research, including in several large trials of acute ischemic stroke interventions, but subsequent analyses have questioned these methods [97]. Learning from these results, some trialists have crafted shorter consent processes as a more practical approach to achieving research aims while preserving patient autonomy [98,99]. However, merely shortening the consent process does not solve the challenges of patient incapacity or surrogate unavailability. Advocates of consent substitute models contend that formal informed consent can be bypassed if core normative demands underpinning the informed consent process are met. One such model proposes that consent may be substituted if an investigational intervention (a) treats a medically urgent need in incapacitated patient; (2) has a comparable risk-benefit ratio to standard of care; (3) does not pose discernible conflict with patient values; (4) carries minimal net risk; and (5) ensures that, when it becomes possible, informed consent for continued research is obtained from patients or surrogates [79,100]. Fins and colleagues describe an approach of "consensus consent" when considering enrolling persons with DoC in clinical trials, which requires involvement and agreement among four parties-the participant's "legally authorized representative, the subject's physician, the clinical investigator, and a lay subject advocate" [101-103]. Others contend that a model of interactive community consultation or public deliberation, whereby salient values and preferences of recovered patients and other key stakeholder groups are ascertained in advance of a planned study, could potentially supplant or supplement the traditional informed consent process in select circumstances [81,104-107]. Despite the proliferation of alternative models to informed consent, ethical debate still exists regarding the optimal form these approaches should take.

As alternative models of consent continue to mature, a precautionary approach that is maximally responsive to the standards articulated by the WMA Declaration of Helsinki and 
local IRB is indicated. Articles $28-30$ of the revised (2013) WMA Declaration of Helsinki emphasize the following:

"For a potential research subject who is incapable of giving informed consent, the physician must seek informed consent from the legally authorised representative. These individuals must not be included in a research study that has no likelihood of benefit for them unless it is intended to promote the health of the group represented by the potential subject, the research cannot instead be performed with persons capable of providing informed consent, and the research entails only minimal risk and minimal burden ... When a potential research subject who is deemed incapable of giving informed consent is able to give assent to decisions about participation in research, the physician must seek that assent in addition to the consent of the legally authorised representative. The potential subject's dissent should be respected ... Research involving subjects who are physically or mentally incapable of giving consent, for example, unconscious patients, may be done only if the physical or mental condition that prevents giving informed consent is a necessary characteristic of the research group. In such circumstances the physician must seek informed consent from the legally authorised representative. If no such representative is available and if the research cannot be delayed, the study may proceed without informed consent provided that the specific reasons for involving subjects with a condition that renders them unable to give informed consent have been stated in the research protocol and the study has been approved by a research ethics committee. Consent to remain in the research must be obtained as soon as possible from the subject or a legally authorised representative" [21].

This approach combines elements of surrogate consent with deferred consent/assent and importantly requires that unconscious patients only be studied if the condition that renders them decisionally incapacitated is a necessary feature of the research being conducted; so, for example, it would not be considered ethically acceptable to enroll a hospitalized patient who is comatose due to TBI in a clinical trial studying a novel antimicrobial for treatment of pneumonia (even if that patient is affected by pneumonia), as the condition that prevents them from personally consenting (TBI) is not a necessary feature of the research group.

A 2020 American Academy of Neurology (AAN) position statement on ethical issues in clinical research in neurology, authored by the Ethics, Law, and Humanities joint committee of the AAN, American Neurological Association, and Child Neurology Society, articulates similar standards for informed consent in situations where participants' decision-making capacity is impaired [108]:

"When impaired decision-making capacity precludes direct fulfillment of the requirement for informed consent, a legally authorized representative may make the decision on the participant's behalf. The 2017 amendment to the Common Rule specifies that, where state law does not specify rules for surrogate decision-making about research, surrogates for medical decision-making can also be considered surrogates for decisions about clinical research (this is the case in most states). The surrogate should use a substituted judgment standard, making the decision based on the participant's historical beliefs and values, as the surrogate believes the participant would, were the participant able to undertake the informed consent process. IRBs may require additional safeguards, such as independent consent monitors, depending on the degree of cognitive incapacity and the study's riskbenefit ratio and complexity. In developing such safeguards, IRBs should make every effort to fully protect participants with dementia and other cognitive impairments, while minimizing impediments to studies of these important conditions. Similarly, in developing safeguards for pediatric participants, IRBs should endeavor to balance rigorous protection for children participating in research, with the minimization of impediments to clinical research on pediatric neurologic disorders. Of note, the informed consent process can be cognitively and emotionally demanding, and every effort should be made to ensure participants' and surrogate decision-makers' comprehension. In addition, where possible, 
researchers should consider disclosing relevant conflicts of interest during the informed consent process" [108].

When involving surrogate decision-makers in discussions surrounding substituted consent for trial participation, it is crucial for investigators to avoid language that might lead to therapeutic misconception or false expectations, to pressure surrogates to enroll, or to suggest that the investigational intervention has established clinical benefit [109-113]. To safeguard against these risks, some investigators first approach the prospective participant's primary medical team about the surrogate's readiness to discuss research opportunities, and only if there is agreement will a trained clinical research coordinator approach the surrogate decision maker in a non-pressured environment with the opportunity to ask any questions and voice any concerns [77]. To ensure adequate comprehension, plain language and interactive informed-consent methods may be adopted incorporating multimedia (e.g., introductory video), interactive questionnaires, and other novel techniques [114-119]. The informed-consent process should ideally clarify, in plain language, why the clinical trial is being performed, who might benefit from the results, how long the trial will last, what will happen if one chooses to take part in the study, what will happen after the study ends, why one might choose not to participate in the study, what other interventions are available, who to call with questions or concerns about the study, possible benefits and risks, what will happen if one wants to drop out after enrolling, whether reimbursement will be offered for participation, what information will be collected through the study, how privacy will be protected, and how results will be disseminated.

Consent ought to be viewed as an ongoing dialectical process, rather than as an episodic requirement [120-122]. If in the course of a trial a participant with DoC experiences recovery (or discovery) of functional communication, investigators should consider approaching the participant to provide information about the study in which they are enrolled, and offer the participant the opportunity to affirm their consent, assent, or dissent, and this decision should be respected. For participants who are found to be covertly conscious - that is, those who appear behaviorally unresponsive to simple commands but demonstrate the ability to volitionally modulate brain activity under active neuroimaging or EEG paradigms-important unanswered questions exist about whether and how investigators should approach obtaining deferred consent. Empirical neuroethics research is needed to better understand the attitudes of patients and families surrounding the optimal approach to involving research participants with emerging consciousness in the consent process, recognizing the pitfalls of assigning too much or too little weight to surrogate indicators of subjective attitudes ascertained through processed neural correlates. Efforts to restore functional communication through brain-computer interfaces and other assistive technologies in persons with covert consciousness are ongoing, and, in the future, they may aid in safeguarding the autonomy and welfare of these especially vulnerable persons and improve the ethical resilience of longitudinal DoC research programs [123-128].

\section{Balancing Benefits and Risks in DoC Clinical Trials}

Preserving participant autonomy through substituted consent is a necessary but not sufficient condition to ensure ethical DoC clinical trial design and deployment. Drawing upon elements from dominant threads of moral philosophy and codes of ethics, Emmanuel and colleagues detail six other ethical requirements in evaluating clinical research: [129].

(1) "Value—enhancements of health or knowledge must be derived from the research";

(2) "Scientific validity - the research must be methodologically rigorous";

(3) "Fair subject selection-scientific objectives, not vulnerability or privilege, and the potential for and distribution of risks and benefits, should determine communities selected as study sites and the inclusion criteria for individual subjects";

(4) "Favorable risk-benefit ratio-within the context of standard clinical practice and the research protocol, risks must be minimized, potential benefits enhanced, and the potential benefits to individuals and knowledge gained for society must outweigh the risks"; 
(5) "Independent review-unaffiliated individuals must review the research and approve, amend, or terminate it";

(6) "Respect for enrolled subjects—subjects should have their privacy protected, the opportunity to withdraw, and their well-being monitored" [129].

Of these elements, determination of the risk-benefit ratio in DoC clinical trials may prove particularly challenging, as participants with DoC typically cannot report on their subjective experiences following an intervention. Risks may thus be unknown or imperceptible, and benefits could be difficult to rigorously appraise. While behavior-based, electrophysiologic, or neuroimaging indices of improvement might be measured, the epistemological gaps between behavior, brain activity, and subjective phenomenology complicate ordinary ascription of subjective states on the sole basis of an observed change in behavior or brain activity. Complicating matters further, instruments intended to measure the broad range of possible outcomes after severe brain injury are coarse and often dichotomized in "favorable" and "unfavorable", categories that are arbitrarily defined by investigators and clinicians rather than by patients and caregivers [130]. Moreover, normative preferences surrounding intensity of treatment in the event of DoC are often unknown, and quality of life within DoC may be difficult to ascertain and track. This lack of uniformity surrounding what constitutes a favorable outcome in persons with DoC complicates the process of determining which factors should qualify as a relevant benefit, and the relative weight of each factor. The imperviousness of subjective psychological experiences of those with DoC could thus lead to skewed risk-benefit assessments when evaluating the promises and pitfalls of novel interventions [131-133].

To improve the understanding and communication of risks and benefits associated with DoC clinical trial participation, investigators should disambiguate direct, indirect, absolute, and relative risks and potential benefits, and when possible, endeavor to estimate the magnitude and likelihood of each [134]. This process has been referred to as component analysis $[135,136]$. Consider the example of a clinical trial investigating the efficacy of a novel drug to promote recovery of consciousness in patients with coma, and which utilizes fMRI signatures of consciousness as a pharmacodynamic biomarker of response (clinicaltrials.gov NCT03814356) [137]. Direct risks might include those posed by the drug itself (e.g., side effects of study drug). Indirect risks might include idiosyncratic interactions with other medications or indirect consequences of prolonged recumbency in the MRI scanner. Potential direct benefits might include the possibility, albeit not guaranteed, that the study drug may help restore consciousness faster than the pace of natural recovery, even if it is made clear that the study is not designed to restore consciousness but rather to understand safety and pharmacokinetics. Indirect potential benefits might include the possibility that information collected from the study may help researchers find novel future treatments, or increased interaction time with clinicians/investigators. The possibility that unknown psychological effects may occur with interventions in persons with DoC should be explained transparently, and clinical equipoise should be confirmed (defined as "a state of genuine uncertainty on the part of the clinical investigator regarding the comparative therapeutic merits of each arm" $[138,139])$. After distinguishing and cataloging potential benefits and risks entailed by a given clinical trial design, investigators should consider possible modifications to the study design to mitigate risks and maximize benefits, evaluate the cumulative balance of foreseeable benefits and risks (both to the subject and society), and determine, with the aid of a local IRB, whether the anticipated cumulative balance of risks and benefits is proportionate and reasonable [134,140-144].

Given the gaps of knowledge that exist in this area, growing opportunities exist for clinicians/investigators to collaborate with neuroethicists to empirically study the nature of benefits and risks of novel DoC interventions, as informed by perspectives of families and other key stakeholders involved in clinical trials [145,146]. 


\section{Handling Investigational Results Pertaining to Consciousness}

The determination of whether, when, and how to disclose research results requires case-by-case consideration, given the plurality of factors that might bear on these decisions and their potential impact on participants, surrogates, and research-data integrity. These questions should be proactively discussed during the study design phase and written into the protocol and consent procedure [147-151]. Consensus has been growing among ethicists, legal scholars, and regulators in favor of more regular return of research results, where appropriate [152], and a 2018 Consensus Study Report of the National Academies of Sciences, Engineering, and Medicine (NASEM) details a vision for "Returning Individual Research Results to Participants: Guidance for a New Research Paradigm" [149]. The NASEM report was commissioned by the Centers for Medicare and Medicaid Services (CMS), the Food and Drug Administration (FDA), and the National Institutes of Health (NIH). The NASEM framework emphasizes that "[a]s the potential value of the result to participants and the feasibility of return increase, the justification for returning results becomes stronger" [149]. Value need not be defined in strictly clinical terms. The NASEM report expounds the following:

"Value in this context means the value of a result from the perspective of the participant and might entail clinical utility or personal utility as well as personal meaning (e.g., lineage information). This participant-centric approach recognizes that the value of a result is not necessarily tied to its use. To clarify, defining value in this way is not meant to imply that each participant needs to be queried regarding the results that would be meaningful to him or her, but it does require the investigator to consider value from the participant perspective rather than from the more traditional clinical perspective. Feasibility is also determined by multiple factors, including potential challenges, the costs and burdens of returning results, whether biospecimens can be linked to a specific participant, and the resources available to communicate the results effectively and appropriately" [149].

Similarly, the HHS Secretary's Advisory Committee on Human Research Protections (SACHRP) has clarified that "there should be due consideration of whether to return individual research results during the design, conduct, and oversight of research, with a general but rebuttable presumption towards disclosure" [153]. In describing the ethical basis for this guidance, SACHRP specifies the following:

"Provision of individual research results to research subjects is supported by the principles of Respect for Persons and Beneficence. Subjects make an autonomous decision to participate in research, and in so doing help to create scientific knowledge that is valuable to society and to other individuals. One means to provide recognition and appreciation for this contribution is to provide subjects with their individual information that results from the research. This can help to build a sense of participation and partnership in the development, and makes their experience more fulfilling. For these reasons, this policy has the potential to lead to greater public trust in research and greater willingness by individuals to participate in research, which will increase the development of new knowledge and interventions for the public good. In addition, the information may (if sufficiently reliable and valid) prove valuable for the subjects or their families in making future decisions regarding their health or welfare, such as future choices about the use of certain classes of drugs or family planning decisions ... the individual results do not have to be of clinical value to the subjects in order for return to be considered. Even if the results are not clinically relevant, the pure intellectual curiosity of the subjects is sufficient reason to return the results absent other reasons not to return them ... SACHRP believes it is often appropriate as an ethical issue to return individual results to research subjects, with a stronger presumption as the validity and actionabililty increase" [153].

Similarly, the Oveido Convention emphasizes that "[e]veryone is entitled to know any information collected about his or her health. However, the wishes of individuals not to be so informed shall be observed" (Article 10) [59]. The salient ethical threads of reciprocity, transparency, beneficence, and autonomy that run through these positions, thus, generally support the return of research results to patients or surrogates. While the 
forgoing positions do not specifically address how these considerations might be affected in contexts where participants are unable to directly consent to participate in research, such as in clinical trials involving patients with DoC, it may reasonably follow from the principles discussed that the propriety of returning research results is amplified in contexts of research participant incapacity.

During a clinical trial or research study involving participants with $\mathrm{DoC}$, it is possible that results will be obtained that shed light on the participant's level of consciousness, including findings suggestive of covert consciousness, or CMD, wherein the level of awareness detected on fMRI and EEG exceeds that which is observed on bedside neurobehavioral examination. In other circumstances, investigational results might challenge the likelihood of conscious awareness or recovery thereof in clinical contexts of diagnostic and prognostic uncertainty. In such circumstances, important questions arise surrounding whether, how, and to whom such investigational results ought to be disclosed, and how to characterize the value of such information [70,146,154-157].

In contrast to typical "incidental findings", results such as these may be anticipated, intentionally sought after (e.g., to aid a clinical team in neuroprognostication), or generated by design [158-161]. Insofar as such results may inform surrogates' and clinical teams' judgements about the presence or absence of consciousness and possibility of recovery, there is a strong ethical case to be made for routine disclosure of investigational results pertaining to consciousness, with appropriate counseling and provision of anticipatory guidance, especially if such information might bear on therapeutic approaches and goals of care conversations. Withholding such information from clinicians or family members, even if the information is investigational in nature and non-conclusive, may be viewed as running contrary to the ethical principles of autonomy, transparency, reciprocity, and beneficence [162-166]. Arguments in favor of non-disclosure may appeal to concerns of affecting the integrity of the research study or study outcomes (e.g., if un-blinding occurs or if the results influence subsequent longitudinal data acquisition), confusing family members or clinicians, reinforcing false hope (in the case of an unduly optimistic study result), or generating false despair (in the case of a unduly pessimistic study result) [167-169]. To manage these concerns and mitigate risks, investigators should work closely with ethicists to develop a standardized approach to sensitively handle investigational results pertaining to the presence or absence of consciousness. Qualitative research findings by Peterson and colleagues have challenged concerns surrounding therapeutic misconception and false hope, suggesting that caregivers generally understood results of advanced neuroimaging pertaining to consciousness and that "pre-disclosure consultations" and standardized methods of disclosure could improve reception and understanding of complex results [156]. To align expectations, surrogate decision-makers should be proactively counseled about the nature of the information that might accrue through study participation and their attitudes toward receiving or not receiving such information gauged. A harmonized process could accordingly be developed, analogous to AAN ethics committee guidance on handling of neurogenetic research findings "with the ultimate objective of providing participants with an option to be informed - or not-of incidentally discovered actionable results during the informed consent process prior to" testing [108]. Investigators should sensitively discuss all clinically relevant findings with the primary medical team, and they should work collaboratively to devise a responsible approach to disclosing results to surrogates in a manner that acknowledges the inherent ambiguities that might be latent in the investigational data and its defeasible interpretation [154,170-173].

As the acquisition of such patient data becomes more common with the guidelinedriven clinical translation of advanced neurotechnologies to detect and predict recovery of consciousness $[174,175]$, these ethical quandaries will undoubtedly evolve and multiply. Nascent opportunities, therefore, exist for embedded neuroethics research to capture and critically evaluate the experiences and perspectives of key stakeholders involved in such studies, particularly surrounding information disclosure practices. Investigators must work closely with clinicians, IRBs, and ethicists to harmonize approaches to disclosing 
such findings to primary medical teams and families, informed by emerging neuroethics principles and research [146].

\section{Advancing Equity in DoC Clinical Trial Access and Enrollment}

Despite an increase in DoC clinical trials over the past decade, access and enrollment remains highly irregular, especially in remote or underserved areas. Racial-, ethnic-, and language-based disparities are also prevalent across a variety of clinical trial domains [176-181]. Ethical considerations of justice and equity demand close attention to these potential disparities and necessitate strategies to democratize access to DoC clinicaltrial enrollment $[67,69,70]$. Research identifying patterns of accrual of participants in DoC clinical trials, characterizing disparities, and illuminating barriers to enrollment is needed to ensure diverse and equitable clinical-trial enrollment. Strategies to enhance access to DoC clinical trials in underserved and remote areas are needed. Hub-and-spoke model systems that rely on networks of central tertiary DoC research hubs with connections to community medical centers may provide a platform for expediently triaging patients in need of specialty DoC management or who might be interested in clinical trial enrollment $[154,182,183]$. Nonetheless, many logistical challenges exist, including financial complexities, transportation across state or country borders, and regulatory barriers. While these challenges have received substantial attention in other fields of research, such as clinical trials for cancer and other disease areas [184-197], their role in DoC research studies has been relatively underexplored and represents a vital area for ongoing advocacy and investigation. Initiatives to enhance equity in clinical-trial enrollment, including resources to promote diverse and inclusive enrollment and training for researchers, have been made available by FDA [198]. The NIH Revitalization Act of 1993, the 21st Century Cures Act (2016), NIH Policy and Guidelines on the Inclusion of Women and Minorities as Subjects in Clinical Research (2017), and the FDA guidance on "Enhancing the Diversity of Clinical Trial Populations-Eligibility Criteria, Enrollment Practices, and Trial Designs Guidance for Industry" (FDA-2019-D-1264) outline additional steps to advance diverse and equitable representation in clinical trials.

\section{Ethically Informed DoC Clinical Trial Design and Execution}

Clinical trials for DoC promise to fill fundamental gaps in intervention and prognostication for some of the most vulnerable and marginalized patients $[199,200]$. Such trials, therefore, present tremendous opportunities, while also raising challenging ethical and social issues. While canvasing every ethical issue pertaining to each type of intervention is well beyond the scope of the present analysis, the framework developed here emphasizes four important shared ethical dimensions of DoC clinical trials that ought to be considered by investigators when designing and executing trials: (1) autonomy and informed consent for persons with liminal consciousness; (2) balancing and communicating atypical and often unknown benefits and risks; (3) disclosure of investigational results pertaining to consciousness to surrogates and clinical teams; and (4) justice considerations, including equitable DoC clinical trial access and accrual (Table 1). Ethics engagement should not be viewed as a regulatory barrier or impediment to research progress, but rather as an opportunity to promote the long-term success, trustworthiness, and resilience of DoC clinical trials and results. There are also emerging funding opportunities to support embedded neuroethics research and scholarship, sponsored by initiatives such as NIH BRAIN [201]. Recognizing that a "one size fits all" approach will likely overlook important normative nuances and needs of each individual trial, investigators should proactively partner with neuroethicists and local IRBs in ensuring ethically informed DoC clinical trial design and execution. 
Table 1. DoC Clinical Trials: Salient Ethical Challenges, Considerations for Researchers \& Selected Regulatory Guidance.

\begin{tabular}{|c|c|c|}
\hline Ethical Challenge & Key Considerations for Researchers & Relevant Regulatory Codes \& Conventions \\
\hline $\begin{array}{l}\text { Autonomy and informed } \\
\text { consent for persons with liminal } \\
\text { consciousness }\end{array}$ & $\begin{array}{l}\text { Voluntary and informed consent is anchored to respect for } \\
\text { autonomy. Instead of disenfranchising patients with DoC } \\
\text { from research participation due to decisional incapacity, } \\
\text { trials involving participants with DoC who cannot consent } \\
\text { must consider alternative pathways to ensure responsible } \\
\text { inclusivity and preserve participant autonomy, including } \\
\text { surrogate consent. }\end{array}$ & $\begin{array}{l}\text { Convention on Human Rights and } \\
\text { Biomedicine (Oveido Convention) } \\
\text { EU regulation No 536/2014 ("clinical trials on } \\
\text { medicinal products for human use"); Directive } \\
2001 / 20 / \text { EC } \\
\text { Code of Federal Regulations (CFR); Common } \\
\text { Rule } \\
\text { Declaration of Helsinki (1964, updated 2013) } \\
\text { Belmont Report }\end{array}$ \\
\hline
\end{tabular}

Determination of risks and benefits in DoC clinical trials may prove particularly challenging, as participants with DoC typically cannot report on their subjective experiences. Risks may thus be unknown or imperceptible, and benefits could be difficult to rigorously appraise. While behavior-based, electrophysiologic, or neuroimaging indices of improvement might be measured, the epistemological gaps between behavior, brain activity and subjective phenomenology complicate ordinary ascription of subjective states on the sole basis of an observed change in behavior or brain activity. To improve the understanding and communication of risks and benefits associated with DoC clinical trial participation, investigators should disambiguate direct, indirect, absolute and relative risks and potential benefits, and when possible, endeavor to estimate the magnitude and likelihood of each [134-136].

Declaration of Helsinki (1964, updated 2013)

Belmont Report

Code of Federal Regulations

NIMH Guidance on Risk-Based Monitoring
During a clinical trial involving participants with DoC, it is possible that results will be obtained that shed light on the participant's level of consciousness and/or capacity for recovery in clinical contexts of diagnostic and prognostic uncertainty. In such circumstances, important questions arise surrounding whether, how and to whom such investigational results ought to be disclosed, and how to characterize the value of such information [70,146,154-157]. Determination of whether, when and how to disclose research results demands case-by-case consideration, given the plurality of factors that might bear on these decisions and their potential impact on participants, surrogates and research data integrity. These questions should be proactively discussed during the study design phase and written into the protocol and consent procedure [147-151]. Consensus has been growing among ethicists, legal scholars and regulators in favor of more regular return of research results where appropriate.

Opportunities exist for embedded neuroethics research to capture and critically evaluate the experiences and perspectives of key stakeholders involved in such studies, particularly surrounding information disclosure practices. Investigators must work closely with clinicians, IRBs and ethicists to harmonize approaches to disclosing such findings to primary medical teams and families, informed by emerging neuroethics principles [146].

Despite an increase in DoC clinical trials over the past decade, access and enrollment remains highly irregular, especially in remote or underserved areas. Racial, ethnic

Justice considerations, including equitable DoC clinical trial access and accrual and language-based disparities are also prevalent across a variety of clinical trial domains. Ethical considerations of justice and equity demand close attention to these potential disparities, and necessitate strategies to democratize access to DoC clinical trial enrollment and enhance representativeness.
HHS Secretary's Advisory Committee on Human Research Protections (SACHRP) Guidance

Convention on Human Rights and Biomedicine (Oveido Convention) 2017 Consensus Study Report of the National Academies of Sciences, Engineering and Medicine (NASEM), “Returning Individual Research Results to Participants: Guidance for a New Research Paradigm." The NASEM framework emphasizes that "[a]s the potential value of the result to participants and the feasibility of return increase, the justification for returning results becomes stronger."
NIH Revitalization Act of 1993

21st Century Cures Act (2016)

NIH Policy and Guidelines on the Inclusion of

Women and Minorities as Subjects in Clinical Research (2017)

FDA Guidance Document (2020) “Enhancing the Diversity of Clinical Trial Populations Eligibility Criteria, Enrollment Practices, and Trial Designs Guidance for Industry" (FDA-2019-D-1264) 
Table 1. Cont.

\begin{tabular}{|c|c|c|}
\hline Ethical Challenge & Key Considerations for Researchers & Relevant Regulatory Codes \& Conventions \\
\hline $\begin{array}{l}\text { Post-trial obligations and } \\
\text { expanded access }\end{array}$ & $\begin{array}{l}\text { Researchers should consider obligations to participants and } \\
\text { surrogates after trial concludes, along with approaches to } \\
\text { expanded access / compassionate use of the investigational } \\
\text { intervention in persons with DoC with no alternative } \\
\text { treatment options. }\end{array}$ & $\begin{array}{l}\text { FDA Guidance Document on Expanded } \\
\text { Access to Investigational Drugs for Treatment } \\
\text { Use (FDA-2013-D-0446, 2021) } \\
\text { NIH Policy 3014-502 - Expanded Access, } \\
\text { Including Emergency Use of Investigational } \\
\text { Drugs, Biologics, and Medical Devices } \\
\text { (Updated 2021) } \\
\text { European Medicines Agency (EMA) Guideline } \\
\text { on compassionate use of medicinal products, } \\
\text { pursuant to Article } 83 \text { of Regulation (EC) No } \\
726 / 2004 \text { (2007) }\end{array}$ \\
\hline
\end{tabular}

Author Contributions: Conceptualization, M.J.Y., Y.G.B., B.L.E.; investigation, M.J.Y.; resources, B.L.E.; data curation, M.J.Y.; writing—original draft preparation, M.J.Y.; writing-review and editing, M.J.Y., Y.G.B., B.L.E.; supervision, Y.G.B., B.L.E. All authors have read and agreed to the published version of the manuscript.

Funding: This work was supported by the NIH BRAIN Initiative (F32MH123001), the NIH National Institute of Neurological Disorders and Stroke (R21NS109627, RF1NS115268), NIH Director's Office (DP2HD101400), James S. McDonnell Foundation, and Tiny Blue Dot Foundation.

Institutional Review Board Statement: Not applicable.

Informed Consent Statement: Not applicable.

Data Availability Statement: Not applicable.

Conflicts of Interest: The authors declare no conflict of interest.

\section{References}

1. Riley, W.T.; Riddle, M.; Lauer, M. NIH policies on experimental studies with humans. Nat. Hum. Behav. 2018, 2, 103-106. [CrossRef] [PubMed]

2. NIH. 2021. Available online: https://www.nih.gov/health-information/nih-clinical-research-trials-you/glossary-commonterms (accessed on 16 December 2021).

3. Schafer, A. The ethics of the randomized clinical trial. N. Engl. J. Med. 1982, 307, 719-724. [CrossRef] [PubMed]

4. Hellman, S.; Hellman, D.S. Of mice but not men: Problems of the randomized clinical trial. N. Engl. J. Med. 1991, 324, 1585-1589. [CrossRef]

5. Passamani, E. Clinical trials-Are they ethical? N. Engl. J. Med. 1991, 324, 1589-1592. [CrossRef] [PubMed]

6. Goldstein, C.E.; Weijer, C.; Brehaut, J.C.; Fergusson, D.A.; Grimshaw, J.M.; Horn, A.R.; Taljaard, M. Ethical issues in pragmatic randomized controlled trials: A review of the recent literature identifies gaps in ethical argumentation. BMC Med. Ethics 2018, 19, 1-10. [CrossRef]

7. May, T. The concept of autonomy. Am. Philos. Q. 1994, 31, 133-144.

8. Berg, J.W.; Appelbaum, P.S.; Lidz, C.W.; Parker, L.S. The concept and ethical justification of informed consent. In Informed Consent; Oxford University Press: Oxford, UK, 2001.

9. Dworkin, G. The Theory and Practice of Autonomy; Cambridge University Press: Cambrigde, UK, 1988.

10. Swaine, L. The Origins of Autonomy. Hist. Political Thought 2016, 37, 216-237.

11. Stoljar, N. Informed consent and relational conceptions of autonomy. J. Med. Philos. 2011, 36, 375-384. [CrossRef]

12. Ursin, L.Ø. Personal autonomy and informed consent. Med. Health Care Philos. 2009, 12, 17-24. [CrossRef]

13. Beauchamp, T.L. Autonomy and consent. In The Ethics of Consent: Theory and Practice; Oxford University Press: Oxford, UK, 2010; pp. $55-78$.

14. Taylor, J.S. Social autonomy and family-based informed consent. J. Med. Philos. A Forum Bioeth. Philos. Med. 2019, 44, 621-639.

15. Rice, T.W. The historical, ethical, and legal background of human-subjects research. Respir. Care 2008, 53, 1325-1329. [PubMed]

16. Weindling, P. The origins of informed consent: The international scientific commission on medical war crimes, and the Nuremberg Code. Bull. Hist. Med. 2001, 75, 37-71. [CrossRef]

17. Beauchamp, T.L. The belmont report. In The Oxford Textbook of Clinical Research Ethic; Oxford University Press: Oxford, UK, 2008; pp. 149-155.

18. World Medical Association Declaration of Helsinki. Ethical Principles for Medical Research Involving Human Subjects. Updated 2013. Available online: https:/ / www.wma.net/policies-post/wma-declaration-of-helsinki-ethical-principles-for-medicalresearch-involving-human-subjects/. (accessed on 1 January 2022). 
19. Beauchamp, T.L.; Childress, J.F. Principles of Biomedical Ethics; Oxford University Press: New York, NY, USA, 2001.

20. Pellegrino, E.D. The Nazi doctors and Nuremberg: Some moral lessons revisited. Ann. Intern. Med. 1997, 127, 307-308. [CrossRef] [PubMed]

21. World Medical Association. World Medical Association Declaration of Helsinki: Ethical principles for medical research involving human subjects. JAMA 2013, 310, 2191-2194. [CrossRef] [PubMed]

22. Food and Drug Administraiton. CFR-Code of federal regulations title 21. Spring 1993, 12, 7-15.

23. Wright, M. Who decides? Legal changes to facilitate inclusion of participants with impaired cognition in research. In Research Involving Participants with Cognitive Disability and Differences: Ethics, Autonomy, Inclusion, and Innovation; Oxford University Press: New York, NY, USA, 2019; pp. 15-26.

24. Orzechowski, M.; Woniak, K.; Timmermann, C.; Steger, F. Normative framework of informed consent in clinical research in Germany, Poland, and Russia. BMC Med. Ethics 2021, 22, 1-10. [CrossRef]

25. Marshall, P.A.; Marshall, P.L. Ethical Challenges in Study Design and Informed Consent for Health Research In Resource-Poor Settings; World Health Organization: Geneva, Switzerland, 2007; Volume 5.

26. Da Silva, R.E.; Amato, A.A.; Guilhem, D.B.; Novaes, M. Globalization of clinical trials: Ethical and regulatory implications. Int. J. Clin. Trials 2016, 3, 1-8. [CrossRef]

27. Abolfotouh, M.A.; Adlan, A.A. Quality of informed consent for invasive procedures in central Saudi Arabia. Int. J. Gen. Med. 2012, 5, 269. [CrossRef]

28. Ibrahim, M.A.; Alshogran, O.Y.; Khabour, O.F.; Alzoubi, K.H. The quality of consent form structure in biomedical research: A study from Jordan and Sudan. J. Multidiscip. Healthc. 2019, 12, 727. [CrossRef]

29. Nakkash, R.; Qutteina, Y.; Nasrallah, C.; Wright, K.; El-Alti, L.; Makhoul, J.; Al-Ali, K. The practice of research ethics in Lebanon and Qatar: Perspectives of researchers on informed consent. J. Empir. Res. Hum. Res. Ethics 2017, 12, 352-362. [CrossRef]

30. Gong, N.; Zhou, Y.; Cheng, Y.; Chen, X.; Li, X.; Wang, X.; Chen, G.; Chen, J.; Meng, H.; Zhang, M. Practice of informed consent in Guangdong, China: A qualitative study from the perspective of in-hospital patients. BMJ Open 2018, 8, e020658. [CrossRef] [PubMed]

31. Jayaraman, K. Outsourcing clinical trials to India rash and risky, critics warn. Nat. Med. 2004, 10, 440-441. [CrossRef] [PubMed]

32. Hanauer, S.B. Outsourcing clinical trials. Nat. Rev. Gastroenterol. Hepatol. 2009, 6, 191. [CrossRef] [PubMed]

33. Cooper, M. Experimental labour-Offshoring clinical trials to China. East Asian Sci. Technol. Soc. Int. J. 2008, 2, 73-92. [CrossRef]

34. Normile, D. The promise and pitfalls of clinical trials overseas. Science 2008, 322, 214-216. [CrossRef]

35. Kamat, V.R. Fast, cheap, and out of control? Speculations and ethical concerns in the conduct of outsourced clinical trials in India. Soc. Sci. Med. 2014, 104, 48-55. [CrossRef]

36. Petryna, A. Ethical variability: Drug development and globalizing clinical trials. Am. Ethnol. 2005, 32, 183-197. [CrossRef]

37. Adobor, $\mathrm{H}$. Ethical issues in outsourcing: The case of contract medical research and the global pharmaceutical industry. J. Bus. Ethics 2012, 105, 239-255. [CrossRef]

38. Normile, D. Genetics papers from China face ethical scrutiny. Science 2021, 373, 727-728. [CrossRef]

39. Cong, Y. Doctor-family-patient relationship: The Chinese paradigm of informed consent. J. Med. Philos. 2004, 29, 149-178 [CrossRef]

40. Raposo, V.L. Lost in 'Culturation': Medical informed consent in China (from a Western perspective). Med. Health Care Philos. 2019, 22, 17-30. [CrossRef] [PubMed]

41. Rui, D. A family-oriented decision-making model for human research in mainland China. J. Med. Philos. A Forum Bioeth. Philos. Med. 2015, 40, 400-417. [CrossRef]

42. Zhang, H.; Tian, L.; Zhang, H.; Zhang, Z.; Wang, Y. Chinese clinical ethicists accept physicians' benevolent deception of patients. Am. J. Bioeth. 2021, 21, 22-24. [CrossRef] [PubMed]

43. Markus, H.R.; Kitayama, S. Culture and the self: Implications for cognition, emotion, and motivation. Psychol. Rev. 1991, 98, 224. [CrossRef]

44. Markus, H.R.; Kitayama, S. Culture, self, and the reality of the social. Psychol. Inq. 2003, 14, 277-283. [CrossRef]

45. Young, M.J. Bioenhancements and the telos of medicine. Med. Health Care Philos. 2015, 18, 515-522. [CrossRef]

46. Shenoy, P. Multi-regional clinical trials and global drug development. Perspect. Clin. Res. 2016, 7, 62. [CrossRef]

47. Thiers, F.A.; Sinskey, A.J.; Berndt, E.R. Trends in the globalization of clinical trials. Nat. Rev. Drug Discov. 2008, 7, 13-14. [CrossRef]

48. Wahlberg, A.; Rehmann-Sutter, C.; Sleeboom-Faulkner, M.; Lu, G.; Döring, O.; Cong, Y.; Laska-Formejster, A.; He, J.; Chen, H.; Gottweis, H. From global bioethics to ethical governance of biomedical research collaborations. Soc. Sci. Med. 2013, 98, 293-300. [CrossRef]

49. Glickman, S.W.; McHutchison, J.G.; Peterson, E.D.; Cairns, C.B.; Harrington, R.A.; Califf, R.M.; Schulman, K.A. Ethical and scientific implications of the globalization of clinical research. N. Engl. J. Med. 2009, 360, 816-823. [CrossRef]

50. Tse, T.; White, S.; Gelinas, L.; Morrell, W.; Bierer, B.; Zarin, D.A. Characterization of Informed Consent Forms Posted on ClinicalTrials. gov. JAMA Netw. Open 2021, 4, e2135146. [CrossRef] [PubMed]

51. Nys, H.; Stultiëns, L.; Borry, P.; Goffin, T.; Dierickx, K. Patient rights in EU Member States after the ratification of the Convention on Human Rights and Biomedicine. Health Policy 2007, 83, 223-235. [CrossRef] [PubMed]

52. Tenti, E.; Simonetti, G.; Bochicchio, M.; Martinelli, G. Main changes in European clinical trials regulation (no 536/2014). Contemp. Clin. Trials Commun. 2018, 11, 99-101. [CrossRef] [PubMed] 
53. Ten Have, H.; Neves, M.d.C.P. Regulation (EU) on Clinical Trials. In Dictionary of Global Bioethics; Springer: New York, NY, USA, 2021; pp. 883-884.

54. Regulation (EU) 2016/679 of the European Parliament and of the Council of 27 April 2016 on the Protection of Natural Persons with Regard to the Processing of Personal Data and on the Free Movement of Such Data, and Repealing Directive 95/46/EC (General Data Protection Regulation) (Text with EEA Relevance) (OJ L 119 04.05.2016, p. 1, CELEX). Available online: https:/ / eur-lex.europa.eu/legal-content/EN/TXT/?uri=CELEX:32016R0679 (accessed on 16 December 2021).

55. Timmers, M.; Van Veen, E.-B.; Maas, A.I.; Kompanje, E.J. Will the Eu data protection regulation 2016/679 inhibit critical care research? Med. Law Rev. 2019, 27, 59-78. [CrossRef] [PubMed]

56. Richter, G.; Borzikowsky, C.; Lieb, W.; Schreiber, S.; Krawczak, M.; Buyx, A. Patient views on research use of clinical data without consent: Legal, but also acceptable? Eur. J. Hum. Genet. 2019, 27, 841-847. [CrossRef]

57. Van Wijk, R.P.; van Dijck, J.T.; Timmers, M.; van Veen, E.; Citerio, G.; Lingsma, H.F.; Maas, A.I.; Menon, D.K.; Peul, W.C.; Stocchetti, $\mathrm{N}$. Informed consent procedures in patients with an acute inability to provide informed consent: Policy and practice in the CENTER-TBI study. J. Crit. Care 2020, 59, 6-15. [CrossRef]

58. Timmers, M.; Van Dijck, J.T.; Van Wijk, R.P.; Legrand, V.; Van Veen, E.; Maas, A.I.; Menon, D.K.; Citerio, G.; Stocchetti, N.; Kompanje, E.J. How do 66 European institutional review boards approve one protocol for an international prospective observational study on traumatic brain injury? Experiences from the CENTER-TBI study. BMC Med. Ethics 2020, 21, 1-14. [CrossRef]

59. The Convention for the Protection of Human Rights and Dignity of the Human Being with Regard to the Application of Biology and Medicine: Convention on Human Rights and Biomedicine (ETS No 164, Oviedo Convention and its Protocols). Available online: https:/ / www.coe.int/en/web/bioethics/oviedo-convention (accessed on 1 January 2022).

60. Scavone, C.; di Mauro, G.; Pietropaolo, M.; Alfano, R.; Berrino, L.; Rossi, F.; Tomino, C.; Capuano, A. The European clinical trials regulation (No 536/2014): Changes and challenges. Expert Rev. Clin. Pharmacol. 2019, 12, 1027-1032. [CrossRef]

61. Blackwood, R.A.; Maio, R.F.; Mrdjenovich, A.J.; VandenBosch, T.M.; Gordon, P.S.; Shipman, E.L.; Hamilton, T.A. Analysis of the nature of IRB contingencies required for informed consent document approval. Account. Res. 2015, 22, 237-245. [CrossRef]

62. Rothwell, E.; Brassil, D.; Barton-Baxter, M.; Brownley, K.A.; Dickert, N.W.; Ford, D.E.; Kraft, S.A.; McCormick, J.B.; Wilfond, B.S. Informed consent: Old and new challenges in the context of the COVID-19 pandemic. J. Clin. Transl. Sci. 2021, 5, e105. [CrossRef]

63. Flume, P.A.; Berbari, E.F.; Viera, L.; Hess, R.; Higgins, J.; Armstrong, J.; Rice, L.; True, L.; Shaker, R.; Buse, J.B. Managing the risks and benefits of clinical research in response to a pandemic. J. Clin. Transl. Sci. 2021, 5, e105. [CrossRef]

64. Largent, E.A.; Halpern, S.D.; Fernandez Lynch, H. Waivers and alterations of research informed consent during the COVID-19 pandemic. Ann. Intern. Med. 2021, 174, 415-416. [CrossRef] [PubMed]

65. Young, M.J. Compassionate care for the unconscious and incapacitated. Am. J. Bioeth. 2020, 20, 55-57. [CrossRef] [PubMed]

66. Edlow, B.L.; Claassen, J.; Schiff, N.D.; Greer, D.M. Recovery from disorders of consciousness: Mechanisms, prognosis and emerging therapies. Nat. Rev. Neurol. 2021, 17, 135-156. [CrossRef] [PubMed]

67. Hammond, F.M.; Katta-Charles, S.; Russell, M.B.; Zafonte, R.D.; Claassen, J.; Wagner, A.K.; Puybasset, L.; Egawa, S.; Laureys, S.; Diringer, M. Research Needs for Prognostic Modeling and Trajectory Analysis in Patients with Disorders of Consciousness. Neurocritical Care 2021, 35, 55-67. [CrossRef]

68. Edlow, B.L.; Sanz, L.R.; Polizzotto, L.; Pouratian, N.; Rolston, J.D.; Snider, S.B.; Thibaut, A.; Stevens, R.D.; Gosseries, O. Therapies to restore consciousness in patients with severe brain injuries: A gap analysis and future directions. Neurocritical care 2021, 35, 68-85. [CrossRef]

69. Peterson, A.; Aas, S.; Wasserman, D. What justifies the allocation of health care resources to patients with disorders of consciousness? AJOB Neurosci. 2021, 12, 127-139. [CrossRef]

70. Young, M.J.; Edlow, B.L. Emerging Consciousness at a Clinical Crossroads. AJOB Neurosci. 2021, 12, 148-150. [CrossRef]

71. Fins, J.J.; Illes, J.; Bernat, J.L.; Hirsch, J.; Laureys, S.; Murphy, E. Neuroimaging and disorders of consciousness: Envisioning an ethical research agenda. Am. J. Bioeth. 2008, 8, 3-12. [CrossRef]

72. Kompanje, E.J.; van Dijck, J.T.; Chalos, V.; van den Berg, S.A.; Janssen, P.M.; Nederkoorn, P.J.; van der Jagt, M.; Citerio, G.; Stocchetti, N.; Dippel, D.W. Informed consent procedures for emergency interventional research in patients with traumatic brain injury and ischaemic stroke. Lancet Neurol. 2020, 19, 1033-1042. [CrossRef]

73. Abramson, N.S.; Meisel, A.; Safar, P. Deferred consent: A new approach for resuscitation research on comatose patients. JAMA 1986, 255, 2466-2471. [CrossRef] [PubMed]

74. Hicks, R. Ethical and regulatory considerations in the design of traumatic brain injury clinical studies. Handb. Clin. Neurol. 2015, 128, 743-759. [PubMed]

75. Lemaire, F. The inability to consent in critical care research: Emergency or impairment of cognitive function? Intensive Care Med. 2006, 32, 1930-1932. [CrossRef] [PubMed]

76. Ecarnot, F.; Quenot, J.-P.; Besch, G.; Piton, G. Ethical challenges involved in obtaining consent for research from patients hospitalized in the intensive care unit. Ann. Transl. Med. 2017, 5, S41. [CrossRef]

77. Bruni, T.; Graham, M.; Norton, L.; Gofton, T.; Owen, A.M.; Weijer, C. Informed consent for functional MRI research on comatose patients following severe brain injury: Balancing the social benefits of research against patient autonomy. J. Med. Ethics 2019, 45, 299-303. [CrossRef] 
78. Geocadin, R.G.; Callaway, C.W.; Fink, E.L.; Golan, E.; Greer, D.M.; Ko, N.U.; Lang, E.; Licht, D.J.; Marino, B.S.; McNair, N.D. Standards for studies of neurological prognostication in comatose survivors of cardiac arrest: A scientific statement from the American Heart Association. Circulation 2019, 140, e517-e542. [CrossRef]

79. Largent, E.A.; Wendler, D.; Emanuel, E.; Miller, F.G. Is emergency research without initial consent justified? The consent substitute model. Arch. Intern. Med. 2010, 170, 668-674. [CrossRef]

80. Chin, T.L.; Moore, E.E.; Coors, M.E.; Chandler, J.G.; Ghasabyan, A.; Harr, J.N.; Stringham, J.R.; Ramos, C.R.; Ammons, S.; Banerjee, A. Exploring ethical conflicts in emergency trauma research: The COMBAT (Control of Major Bleeding after Trauma) study experience. Surgery 2015, 157, 10-19. [CrossRef]

81. Powers, P.E.; Shore, K.K.; Perez, S.; Ritley, D.; Kuppermann, N.; Holmes, J.F.; Tzimenatos, L.S.; Shawargga, H.; Nishijima, D.K. Public Deliberation as a Novel Method for an Exception From Informed Consent Community Consultation. Acad. Emerg. Med. 2019, 26, 1158-1168. [CrossRef]

82. Feldman, W.B.; Hey, S.P.; Franklin, J.M.; Kesselheim, A.S. Public Approval of Exception From Informed Consent in Emergency Clinical Trials: A Systematic Review of Community Consultation Surveys. JAMA Netw. Open 2019, 2, e197591. [CrossRef]

83. Carlson, J.N.; Zive, D.; Griffiths, D.; Brown, K.N.; Schmicker, R.H.; Herren, H.; Sopko, G.; DiFiore, S.; Climer, D.; Herdeman, C. Variations in the application of exception from informed consent in a multicenter clinical trial. Resuscitation 2019, 135, 1-5. [CrossRef] [PubMed]

84. Dickert, N.W.; Mah, V.A.; Biros, M.H.; Harney, D.M.; Silbergleit, R.; Sugarman, J.; Veledar, E.; Weinfurt, K.P.; Wright, D.W.; Pentz, R.D. Consulting Communities When Patients Cannot Consent: A Multi-Center Study of Community Consultation for Research in Emergency Settings. Crit. Care Med. 2014, 42, 272. [CrossRef] [PubMed]

85. Dickert, N.W.; Scicluna, V.M.; Baren, J.M.; Biros, M.H.; Fleischman, R.J.; Govindarajan, P.R.; Jones, E.B.; Pancioli, A.M.; Wright, D.W.; Pentz, R.D. Patients' Perspectives of Enrollment in Research Without Consent-The Patients' Experiences in Emergency Research-ProTECT Study (PEER-ProTECT). Crit. Care Med. 2015, 43, 603. [CrossRef] [PubMed]

86. Robertsen, A.; Jöbges, S.; Sadovnikoff, N. Consent, advance directives, and decision by proxies. In Compelling Ethical Challenges in Critical Care and Emergency Medicine; Springer: New York, NY, USA, 2020; pp. 35-47.

87. Burns, K.E.; Prats, C.J.; Maione, M.; Lanceta, M.; Zubrinich, C.; Jeffs, L.; Smith, O.M. The experience of surrogate decision makers on being approached for consent for patient participation in research. A multicenter study. Ann. Am. Thorac. Soc. 2017, 14, 238-245. [PubMed]

88. Blackstone, E.; Daly, B.J.; Griggins, C. Making medical decisions for incapacitated patients without proxies: Part II. In Hec Forum; Springer: Amsterdam, The Netherlands, 2020; p. 4762.

89. Reich, B. Surrogate decision-making: Clinical uncertainty, rational apathy, and the problem of trust. Ethics Med. Public Health 2020, 15, 100523. [CrossRef]

90. Shepherd, V.; Hood, K.; Sheehan, M.; Griffith, R.; Wood, F. 'It's a tough decision': A qualitative study of proxy decision-making for research involving adults who lack capacity to consent in UK. Age Ageing 2019, 48, 903-909. [CrossRef]

91. Shepherd, V. An under-represented and underserved population in trials: Methodological, structural, and systemic barriers to the inclusion of adults lacking capacity to consent. Trials 2020, 21, 1-8. [CrossRef]

92. Shepherd, V. Advances and challenges in conducting ethical trials involving populations lacking capacity to consent: A decade in review. Contemp. Clin. Trials 2020, 95, 106054. [CrossRef]

93. Shepherd, V.; Sheehan, M.; Hood, K.; Griffith, R.; Wood, F. Constructing authentic decisions: Proxy decision making for research involving adults who lack capacity to consent. J. Med. Ethics 2021, 47, e42. [CrossRef]

94. Klein, L.; Moore, J.; Biros, M. A 20-year review: The use of exception from informed consent and waiver of informed consent in emergency research. Acad. Emerg. Med. 2018, 25, 1169-1177. [CrossRef]

95. Feldman, W.B.; Hey, S.P.; Kesselheim, A.S. A systematic review of the Food and Drug Administration's 'exception from informed consent'pathway. Health Aff. 2018, 37, 1605-1614. [CrossRef]

96. Kasner, S.E.; Baren, J.M.; Le Roux, P.D.; Nathanson, P.G.; Lamond, K.; Rosenberg, S.L.; Karlawish, J. Community views on neurologic emergency treatment trials. Ann. Emerg. Med. 2011, 57, 346-354.e6. [CrossRef] [PubMed]

97. Shamy, M.C.; Dewar, B.; Chevrier, S.; Wang, C.-Q.; Page, S.; Goyal, M.; Demchuk, A.M.; Hill, M.D. Deferral of Consent in Acute Stroke Trials: Lessons From the ESCAPE Trial. Stroke 2019, 50, 1017-1020. [CrossRef] [PubMed]

98. Corneli, A.; Namey, E.; Mueller, M.P.; Tharaldson, J.; Sortijas, S.; Grey, T.; Sugarman, J. Evidence-based strategies for shortening informed consent forms in clinical research. J. Empir. Res. Hum. Res. Ethics 2017, 12, 14-25. [CrossRef]

99. Stunkel, L.; Benson, M.; McLellan, L.; Sinaii, N.; Bedarida, G.; Emanuel, E.; Grady, C. Comprehension and informed consent: Assessing the effect of a short consent form. IRB 2010, 32, 1. [PubMed]

100. Dickert, N.W.; Brown, J.; Cairns, C.B.; Eaves-Leanos, A.; Goldkind, S.F.; Kim, S.Y.; Nichol, G.; O'Conor, K.J.; Scott, J.D.; Sinert, R. Confronting ethical and regulatory challenges of emergency care research with conscious patients. Ann. Emerg. Med. 2016, 67, 538-545. [CrossRef] [PubMed]

101. Fins, J.J.; Miller, F.G. Enrolling decisionally incapacitated subjects in neuropsychiatric research. CNS Spectr. $2000,5,32-42$. [CrossRef] [PubMed]

102. Miller, F.G.; Fins, J.J. Protecting human subjects in brain research: A pragmatic perspective. In Neuroethics: Defining the Issues in Theory, Practice and Policy; Oxford University Press: Oxford, UK, 2005. 
103. Fins, J.J. Mosaic decisionmaking and reemergent agency after severe brain injury. Camb. Q. Healthc. Ethics 2018, 27, 163-174. [CrossRef]

104. Bhutta, Z.A. Beyond informed consent. Bull. World Health Organ. 2004, 82, 771-777.

105. Sim, J.; Dawson, A. Informed consent and cluster-randomized trials. Am. J. Public Health 2012, 102, 480-485. [CrossRef]

106. Dickert, N.; Sugarman, J. Ethical goals of community consultation in research. Am. J. Public Health 2005, 95, 1123-1127. [CrossRef] [PubMed]

107. Dickert, N.W.; Metz, K.; Fetters, M.D.; Haggins, A.N.; Harney, D.K.; Speight, C.D.; Silbergleit, R. Meeting unique requirements: Community consultation and public disclosure for research in emergency setting using exception from informed consent. Acad. Emerg. Med. 2021, 28, 1183-1194. [CrossRef] [PubMed]

108. Tolchin, B.; Conwit, R.; Epstein, L.G.; Russell, J.A. AAN position statement: Ethical issues in clinical research in neurology. Neurology 2020, 94, 661-669. [CrossRef] [PubMed]

109. Appelbaum, P.S.; Lidz, C.W.; Grisso, T. Therapeutic misconception in clinical research: Frequency and risk factors. IRB Ethics Hum. Res. 2004, 26, 1-8. [CrossRef]

110. Appelbaum, P.S.; Roth, L.H.; Lidz, C.W.; Benson, P.; Winslade, W. False hopes and best data: Consent to research and the therapeutic misconception. Hastings Cent. Rep. 1987, 17, 20-24. [CrossRef]

111. Henderson, G.E.; Churchill, L.R.; Davis, A.M.; Easter, M.M.; Grady, C.; Joffe, S.; Kass, N.; King, N.M.P.; Lidz, C.W.; Miller, F.G. Clinical trials and medical care: Defining the therapeutic misconception. PLoS Med. 2007, 4, e324. [CrossRef]

112. Jansen, L.A. Informed consent, therapeutic misconception, and unrealistic optimism. Perspect. Biol. Med. 2020, 63, 359-373. [CrossRef]

113. Fins, J.J. Neuroethics and disorders of consciousness: Discerning brain states in clinical practice and research. AMA J. Ethics 2016, $18,1182-1191$

114. Rowbotham, M.C.; Astin, J.; Greene, K.; Cummings, S.R. Interactive informed consent: Randomized comparison with paper consents. PLoS ONE 2013, 8, e58603. [CrossRef]

115. Lentz, J.; Kennett, M.; Perlmutter, J.; Forrest, A. Paving the way to a more effective informed consent process: Recommendations from the Clinical Trials Transformation Initiative. Contemp. Clin. Trials 2016, 49, 65-69. [CrossRef]

116. Synnot, A.; Ryan, R.; Prictor, M.; Fetherstonhaugh, D.; Parker, B. Audio-visual presentation of information for informed consent for participation in clinical trials. Cochrane Database Syst. Rev. 2014, 5, 1-123. [CrossRef] [PubMed]

117. Hughson, J.-a.; Woodward-Kron, R.; Parker, A.; Hajek, J.; Bresin, A.; Knoch, U.; Phan, T.; Story, D. A review of approaches to improve participation of culturally and linguistically diverse populations in clinical trials. Trials 2016, 17, 1-10. [CrossRef] [PubMed]

118. Grady, C.; Cummings, S.R.; Rowbotham, M.C.; McConnell, M.V.; Ashley, E.A.; Kang, G. The changing face of informed consent. N. Engl. J. Med. 2017, 376, 856-859. [CrossRef]

119. Anderson, E.E.; Newman, S.B.; Matthews, A.K. Improving informed consent: Stakeholder views. AJOB Empir. Bioeth. 2017, 8 , 178-188. [CrossRef] [PubMed]

120. O'Reilly, M.; Parker, N.; Hutchby, I. Ongoing processes of managing consent: The empirical ethics of using video-recording in clinical practice and research. Clin. Ethics 2011, 6, 179-185. [CrossRef]

121. Wilson, E.; Pollock, K.; Aubeeluck, A. Gaining and maintaining consent when capacity can be an issue: A research study with people with Huntington's disease. Clin. Ethics 2010, 5, 142-147. [CrossRef]

122. Rubin, E.B.; Bernat, J.L. Consent issues in neurology. Neurol. Clin. 2010, 28, 459-473. [CrossRef] [PubMed]

123. Young, M.J.; Lin, D.J.; Hochberg, L.R. Brain-Computer Interfaces in Neurorecovery and Neurorehabilitation. In Seminars in Neurology; Thieme Medical Publishers, Inc.: New York, NY, USA, 2021.

124. Rubin, D.B.; Paulk, A.C. Neuron, control thyself! Brain 2021, 144, 3550-3551. [CrossRef]

125. Annen, J.; Laureys, S.; Gosseries, O. Brain-computer interfaces for consciousness assessment and communication in severely brain-injured patients. In Handbook of Clinical Neurology; Elsevier: Amsterdam, The Netherlands, 2020; Volume 168, pp. 137-152.

126. Klein, E. Ethics and the emergence of brain-computer interface medicine. In Handbook of Clinical Neurology; Elsevier: Amsterdam, The Netherlands, 2020; Volume 168, pp. 329-339.

127. Glannon, W. Neural Prosthetics: Neuroscientific and Philosophical Aspects of Changing the Brain; Oxford University Press: Oxford, UK, 2021.

128. Young, M.J. Brain-computer interfaces and the philosophy of action. AJOB Neurosci. 2020, 11, 4-6. [CrossRef]

129. Emanuel, E.J.; Wendler, D.; Grady, C. What makes clinical research ethical? JAMA 2000, 283, 2701-2711. [CrossRef]

130. Zuckerman, D.; Giacino, J.; Bodien, Y. Traumatic brain injury: What is a favorable outcome? J. Neurotrauma 2021. [CrossRef] [PubMed]

131. Scott, G.; Carhart-Harris, R.L. Psychedelics as a treatment for disorders of consciousness. Neurosci. Conscious. 2019, 2019 , niz003. [CrossRef]

132. Smith, W.R.; Sisti, D. Ethics and ego dissolution: The case of psilocybin. J. Med. Ethics 2021, 47, 807-814. [CrossRef] [PubMed]

133. Peterson, A.; Tagliazucchi, E.; Weijer, C. The ethics of psychedelic research in disorders of consciousness. Neurosci. Conscious. 2019, 2019, niz013. [CrossRef]

134. Rid, A.; Wendler, D. A framework for risk-benefit evaluations in biomedical research. Kennedy Inst. Ethics J. 2011, 21, 141-179. [CrossRef] 
135. Binik, A.; Hey, S.P. A framework for assessing scientific merit in ethical review of clinical research. Ethics Hum. Res. 2019, 41, 2-13. [CrossRef] [PubMed]

136. Weijer, C. The ethical analysis of risk. J. Law Med. Ethics 2000, 28, 344-361. [CrossRef] [PubMed]

137. Edlow, B.L.; Barra, M.E.; Zhou, D.W.; Foulkes, A.S.; Snider, S.B.; Threlkeld, Z.D.; Chakravarty, S.; Kirsch, J.E.; Chan, S.-t.; Meisler, S.L. Personalized connectome mapping to guide targeted therapy and promote recovery of consciousness in the intensive care unit. Neurocritical Care 2020, 33, 364-375. [CrossRef]

138. Freedman, B. Equipoise and the ethics of clinical research. N. Engl. J. Med. 1987, 317, 141-145. [CrossRef]

139. Halpern, S.D. Evidence-based equipoise and research responsiveness. Am. J. Bioeth. 2006, 6, 1-4. [CrossRef]

140. Bernabe, R.D.; van Thiel, G.J.; Raaijmakers, J.A.; van Delden, J.J. The risk-benefit task of research ethics committees: An evaluation of current approaches and the need to incorporate decision studies methods. BMC Med. Ethics 2012, 13, 1-9. [CrossRef]

141. Bromwich, D.; Rid, A. Can informed consent to research be adapted to risk? J. Med. Ethics 2015, 41, 521-528. [CrossRef] [PubMed]

142. Resnik, D.B. Examining the social benefits principle in research with human participants. Health Care Anal. 2018, 26, 66-80. [CrossRef]

143. Rid, A. Setting risk thresholds in biomedical research: Lessons from the debate about minimal risk. Monash Bioeth. Rev. 2014, 32, 63-85. [CrossRef] [PubMed]

144. Bernabe, R.D.; van Thiel, G.J.; Raaijmakers, J.A.; van Delden, J.J. Decision theory and the evaluation of risks and benefits of clinical trials. Drug Discov. Today 2012, 17, 1263-1269. [CrossRef] [PubMed]

145. Young, M.J. Neuroethics: An Emerging Career Path in Neurology. Neurology 2022. forthcoming.

146. Young, M.J.; Edlow, B.L. The quest for covert consciousness: Bringing neuroethics to the bedside. Neurology 2021, 96, 893-896. [CrossRef]

147. Long, C.R.; Purvis, R.S.; Flood-Grady, E.; Kimminau, K.S.; Rhyne, R.L.; Burge, M.R.; Stewart, M.K.; Jenkins, A.J.; James, L.P.; McElfish, P.A. Health researchers' experiences, perceptions and barriers related to sharing study results with participants. Health Res. Policy Syst. 2019, 17, 1-11. [CrossRef]

148. Purvis, R.S.; Long, C.R.; Eisenberg, L.R.; Hester, D.M.; Cunningham, T.V.; Holland, A.; Chatrathi, H.E.; McElfish, P.A. First Do No Harm: Ethical Concerns of Health Researchers That Discourage the Sharing of Results With Research Participants. AJOB Empir. Bioeth. 2020, 11, 104-113. [CrossRef]

149. National Academies of Sciences, Engineering, Medicine. Returning Individual Research Results to Participants: Guidance for a New Research Paradigm; The National Academic Press: Washington, DC, USA, 2018.

150. Wolf, S.M.; Evans, B.J. Return of results and data to study participants. Science 2018, 362, 159-160. [CrossRef]

151. Sayeed, S.; Califf, R.; Green, R.; Wong, C.; Mahaffey, K.; Gambhir, S.S.; Mega, J.; Patrick-Lake, B.; Frazier, K.; Pignone, M. Return of individual research results: What do participants prefer and expect? PLoS ONE 2021, 16, e0254153. [CrossRef]

152. Wilkins, C.H.; Mapes, B.M.; Jerome, R.N.; Villalta-Gil, V.; Pulley, J.M.; Harris, P.A. Understanding what information is valued by research participants, and why. Health Aff. 2019, 38, 399-407. [CrossRef]

153. Attachment B: Return of Individual Research Results—Sharing Study Data and Results: Return of Individual Results. Available online: https:/ / www.hhs.gov/ohrp/sachrp-committee/recommendations/attachment-b-return-individual-research-results/ index.html. (accessed on 2 January 2022).

154. Young, M.J.; Bodien, Y.G.; Giacino, J.T.; Fins, J.J.; Truog, R.D.; Hochberg, L.R.; Edlow, B.L. The neuroethics of disorders of consciousness: A brief history of evolving ideas. Brain 2021, 144, 3291-3310. [CrossRef]

155. Peterson, A. How Will Families React to Evidence of Covert Consciousness in Brain-Injured Patients? Neuroethics 2020, 14, 347-350. [CrossRef]

156. Peterson, A.; Webster, F.; Gonzalez-Lara, L.E.; Munce, S.; Owen, A.M.; Weijer, C. Caregiver reactions to neuroimaging evidence of covert consciousness in patients with severe brain injury: A qualitative interview study. BMC Med. Ethics 2021, 22, 1-13. [CrossRef] [PubMed]

157. Kuehlmeyer, K.; Bender, A.; Jox, R.J.; Racine, E.; Ruhfass, M.; Schembs, L. Next of kin's Reactions to Results of Functional Neurodiagnostics of Disorders of Consciousness: A Question of Information Delivery or of Differing Epistemic Beliefs? Neuroethics 2021, 14, 357-363. [CrossRef]

158. Murphy, N.; Weijer, C. Grey Matter-The Problems of Incidental Findings in Neuroimaging Research. J. Law Med. Ethics 2021, 49, 282-284. [CrossRef]

159. Ogbuka, C. Managing serious incidental findings in brain imaging research: When consent for disclosure is declined. J. Cogn. Neuroeth. 2014, 2, 51-59.

160. Illes, J.; Kirschen, M.P.; Karetsky, K.; Kelly, M.; Saha, A.; Desmond, J.E.; Raffin, T.A.; Glover, G.H.; Atlas, S.W. Discovery and disclosure of incidental findings in neuroimaging research. J. Magn. Reson. Imaging Off. J. Int. Soc. Magn. Reson. Med. 2004, 20, 743-747. [CrossRef]

161. Edlow, B.L.; Fins, J.J. Assessment of covert consciousness in the intensive care unit: Clinical and ethical considerations. J. Head Trauma Rehabil. 2018, 33, 424. [CrossRef]

162. Fins, J.J. Neuroethics and neuroimaging: Moving toward transparency. Am. J. Bioeth. 2008, 8, 46-52. [CrossRef]

163. Bonini, S.; Eichler, H.-G.; Wathion, N.; Rasi, G. Transparency and the European Medicines Agency-sharing of clinical trial data. N. Engl. J. Med. 2014, 371, 2452-2455. [CrossRef] [PubMed] 
164. Shalowitz, D.I.; Miller, F.G. Disclosing individual results of clinical research: Implications of respect for participants. JAMA 2005, 294, 737-740. [CrossRef] [PubMed]

165. Fadda, M.; Fiordelli, M.; Amati, R.; Falvo, I.; Ibnidris, A.; Hurst, S.; Albanese, E. Returning individual-specific results of a dementia prevalence study: Insights from prospective participants living in Switzerland. Int. J. Geriatr. Psychiatry 2021, 36, 207-214. [CrossRef]

166. Wolf, S.M. Return of Results in Participant-Driven Research: Learning from Transformative Research Models. J. Law Med. Ethics 2020, 48, 159-166. [CrossRef] [PubMed]

167. Young, M.J.; Brown, S.E.; Truog, R.D.; Halpern, S.D. Rationing in the intensive care unit: To disclose or disguise? Crit. Care Med. 2012, 40, 261-266. [CrossRef] [PubMed]

168. Heinrichs, B. A new challenge for research ethics: Incidental findings in neuroimaging. J. Bioethical Inq. 2011, 8, 59-65. [CrossRef]

169. Bhatia, A.; Appelbaum, P.S.; Wisner, K.L. Unblinding in Randomized Controlled Trials: A Research Ethics Case. Ethics Hum. Res. 2021, 43, 28-34. [CrossRef]

170. Fins, J.J.; Bernat, J.L. Ethical, palliative, and policy considerations in disorders of consciousness. Neurology 2018, 91, 471-475. [CrossRef]

171. Weijer, C.; Bruni, T.; Gofton, T.; Young, G.B.; Norton, L.; Peterson, A.; Owen, A.M. Ethical considerations in functional magnetic resonance imaging research in acutely comatose patients. Brain 2016, 139, 292. [CrossRef]

172. Graham, M.; Weijer, C.; Peterson, A.; Naci, L.; Cruse, D.; Fernández-Espejo, D.; Gonzalez-Lara, L.; Owen, A.M. Acknowledging awareness: Informing families of individual research results for patients in the vegetative state. J. Med. Ethics 2015, 41, 534-538. [CrossRef] [PubMed]

173. Peterson, A.; Cruse, D.; Naci, L.; Weijer, C.; Owen, A.M. Risk, diagnostic error, and the clinical science of consciousness NeuroImage Clin. 2015, 7, 588-597. [CrossRef]

174. Giacino, J.T.; Katz, D.I.; Schiff, N.D.; Whyte, J.; Ashman, E.J.; Ashwal, S.; Barbano, R.; Hammond, F.M.; Laureys, S.; Ling, G.S Practice guideline update recommendations summary: Disorders of consciousness: Report of the Guideline Development, Dissemination, and Implementation Subcommittee of the American Academy of Neurology; the American Congress of Rehabilitation Medicine; and the National Institute on Disability, Independent Living, and Rehabilitation Research. Arch. Phys. Med. Rehabil. 2018, 99, 1699-1709. [PubMed]

175. Kondziella, D.; Bender, A.; Diserens, K.; van Erp, W.; Estraneo, A.; Formisano, R.; Laureys, S.; Naccache, L.; Ozturk, S.; Rohaut, B. European Academy of Neurology guideline on the diagnosis of coma and other disorders of consciousness. Eur. J. Neurol. 2020, 27, 741-756. [CrossRef] [PubMed]

176. Leiter, A.; Diefenbach, M.A.; Doucette, J.; Oh, W.K.; Galsky, M.D. Clinical trial awareness: Changes over time and sociodemographic disparities. Clin. Trials 2015, 12, 215-223. [CrossRef]

177. Raman, R.; Quiroz, Y.T.; Langford, O.; Choi, J.; Ritchie, M.; Baumgartner, M.; Rentz, D.; Aggarwal, N.T.; Aisen, P.; Sperling, R. Disparities by race and ethnicity among adults recruited for a preclinical Alzheimer disease trial. JAMA Netw. Open 2021, 4, e2114364. [CrossRef]

178. Milne, R.; Altomare, D.; Ribaldi, F.; Molinuevo, J.L.; Frisoni, G.B.; Brayne, C. Societal and equity challenges for Brain Health Services. A user manual for Brain Health Services-Part 6 of 6. Alzheimer's Res. Ther. 2021, 13, 1-8. [CrossRef]

179. Wilkins, C.H.; Schindler, S.E.; Morris, J.C. Addressing health disparities among minority populations: Why clinical trial recruitment is not enough. JAMA Neurol. 2020, 77, 1063-1064. [CrossRef]

180. Culbert, M.; Oladeru, O.T. Clinical Trial Enrollment of Racial, Ethnic, and Underrepresented Groups-Leveraging a Digital Infrastructure. JAMA Oncol. 2021, 7, 1447-1448. [CrossRef]

181. Brown, C.E.; Curtis, J.R. Time for a New Approach Investigating and Eliminating Racial Inequities in the ICU. Crit. Care Med. 2022, 50, 144-147. [CrossRef]

182. Fins, J.J. Disorders of consciousness and disordered care: Families, caregivers, and narratives of necessity. Arch. Phys. Med. Rehabil. 2013, 94, 1934-1939. [CrossRef] [PubMed]

183. Berube, J.; Fins, J.J.; Giacino, J.; Katz, D.; Langlois, J.; Whyte, J.; Zitnay, G. The Mohonk Report: A Report to Congress Improving Outcomes for Individuals with Disorders of Consciousness; National Brain Injury Research, Treatment \& Training Foundation: Charlottesville, VA, USA, 2006.

184. Nipp, R.D.; Hong, K.; Paskett, E.D. Overcoming barriers to clinical trial enrollment. Am. Soc. Clin. Oncol. Educ. Book 2019, 39, 105-114. [CrossRef] [PubMed]

185. Borno, H.T.; Zhang, L.; Siegel, A.; Chang, E.; Ryan, C.J. At what cost to clinical trial enrollment? A retrospective study of patient travel burden in cancer clinical trials. Oncologist 2018, 23, 1242. [CrossRef] [PubMed]

186. Unger, J.M.; Cook, E.; Tai, E.; Bleyer, A. The role of clinical trial participation in cancer research: Barriers, evidence, and strategies Am. Soc. Clin. Oncol. Educ. Book 2016, 36, 185-198. [CrossRef] [PubMed]

187. Heller, C.; Balls-Berry, J.E.; Nery, J.D.; Erwin, P.J.; Littleton, D.; Kim, M.; Kuo, W.P. Strategies addressing barriers to clinical trial enrollment of underrepresented populations: A systematic review. Contemp. Clin. Trials 2014, 39, 169-182. [CrossRef]

188. Nipp, R.D.; Lee, H.; Gorton, E.; Lichtenstein, M.; Kuchukhidze, S.; Park, E.; Chabner, B.A.; Moy, B. Addressing the financial burden of cancer clinical trial participation: Longitudinal effects of an equity intervention. Oncologist 2019, 24, 1048. [CrossRef] 
189. Penberthy, L.; Brown, R.; Wilson-Genderson, M.; Dahman, B.; Ginder, G.; Siminoff, L.A. Barriers to therapeutic clinical trials enrollment: Differences between African-American and white cancer patients identified at the time of eligibility assessment. Clin. Trials 2012, 9, 788-797. [CrossRef]

190. Eskander, M.F.; Gil, L.; Beal, E.W.; Li, Y.; Hamad, A.; Oppong, B.; Obeng-Gyasi, S.; Tsung, A. Access denied: Inequities in clinical trial enrollment for pancreatic cancer. Ann. Surg. Oncol. 2021, 29, 1271-1277. [CrossRef]

191. Nipp, R.D.; Powell, E.; Chabner, B.; Moy, B. Recognizing the financial burden of cancer patients in clinical trials. Oncologist 2015, 20, 572. [CrossRef]

192. Habr, D.; Ferdinand, R. Addressing racial/ethnic disparities in cancer clinical trials: Everyone has a role to play. Cancer 2021, 127, 3282-3289. [CrossRef]

193. Wallington, S.F.; Dash, C.; Sheppard, V.B.; Goode, T.D.; Oppong, B.A.; Dodson, E.E.; Hamilton, R.N.; Adams-Campbell, L.L. Enrolling minority and underserved populations in cancer clinical research. Am. J. Prev. Med. 2016, 50, 111-117. [CrossRef] [PubMed]

194. Lee, E.Q.; Chukwueke, U.N.; Hervey-Jumper, S.L.; De Groot, J.F.; Leone, J.P.; Armstrong, T.S.; Chang, S.M.; Arons, D.; Oliver, K.; Verble, K. Barriers to accrual and enrollment in brain tumor trials. Neuro-Oncology 2019, 21, 1100-1117. [CrossRef] [PubMed]

195. Young, M.J.; Regenhardt, R.W.; Leslie-Mazwi, T.M.; Stein, M.A. Disabling stroke in persons already with a disability: Ethical dimensions and directives. Neurology 2020, 94, 306-310. [CrossRef] [PubMed]

196. Regenhardt, R.W.; Young, M.J.; Etherton, M.R.; Das, A.S.; Stapleton, C.J.; Patel, A.B.; Lev, M.H.; Hirsch, J.A.; Rost, N.S.; Leslie-Mazwi, T.M. Toward a more inclusive paradigm: Thrombectomy for stroke patients with pre-existing disabilities. $J$. Neurointerventional Surg. 2021, 13, 865-868. [CrossRef] [PubMed]

197. Young, M.J.; Regenhardt, R.W.; Sokol, L.L.; Leslie-Mazwi, T.M. When Should Neuroendovascular Care for Patients With Acute Stroke Be Palliative? AMA J. Ethics 2021, 23, 783-793.

198. FDA. Enhance EQUITY in Clinical Trials. Available online: https://www.fda.gov/consumers/enhance-equity-initiative/ enhance-equity-clinical-trials. (accessed on 3 January 2022).

199. Provencio, J.J.; Hemphill, J.C.; Claassen, J.; Edlow, B.L.; Helbok, R.; Vespa, P.M.; Diringer, M.N.; Polizzotto, L.; Shutter, L.; Suarez, J.I.; et al. The curing coma campaign: Framing initial scientific challenges-Proceedings of the first curing coma campaign scientific advisory council meeting. In Neurocritical Care; Springer: New York, NY, USA, 2020; pp. 1-12.

200. Fins, J.J. Rights Come to Mind: Brain Injury, Ethics, and the Struggle for Consciousness; Cambridge University Press: Cambridge, UK, 2015.

201. Ramos, K.M.; Grady, C.; Greely, H.T.; Chiong, W.; Eberwine, J.; Farahany, N.A.; Johnson, L.S.M.; Hyman, B.T.; Hyman, S.E.; Rommelfanger, K.S. The NIH BRAIN initiative: Integrating neuroethics and neuroscience. Neuron 2019, 101, 394-398. [CrossRef] 